\title{
Nucleosomal association and altered interactome underlie the mechanism of cataract caused by the R54C mutation of $\alpha \mathrm{A}$-crystallin
}

Saad M. Ahsan, Bakthisaran Raman, Tangirala Ramakrishna, Ch. Mohan Rao*

Centre for Cellular and Molecular Biology (CCMB), Uppal Road, Hyderabad - 500 007, Telangana State, India

${ }^{*}$ Corresponding author

Email: mohan@ccmb.res.in

Address: Dr. Ch. Mohan Rao

Centre for Cellular and Molecular Biology (CCMB),

Hyderabad 500 007, India

Ph.No.- $+91-40-27192543$ 


\section{Abstract}

The small heat shock protein (sHSP), aA-crystallin, plays an important role in eye lens development. It has three distinct domains viz. the N-terminal domain, a-crystallin domain and the $\mathrm{C}$-terminal extension. While the a-crystallin domain is conserved across the sHSP family, the $\mathrm{N}$-terminal domain and the $\mathrm{C}$-terminal extension are comparatively less conserved. Nevertheless, certain arginine residues in the $\mathrm{N}$-terminal region of aAcrystallin are conserved across the sHSP family. Interestingly, most of the cataractcausing mutations in aA-crystallin occur in the conserved arginine residues. In order to understand the molecular basis of cataract caused by the R54C mutation in human aAcrystallin, we have compared the structure, chaperone activity, intracellular localization, effect on cell viability and "interactome" of wild-type and mutant aA-crystallin. Although R54CaA-crystallin exhibited slight changes in quaternary structure, its chaperone activity was comparable to that of the wild-type. When expressed in lens epithelial cells, R54CaA-crystallin triggered a stress-like response, resulting in nuclear translocation of aB-crystallin, disassembly of cytoskeletal elements and activation of Caspase 3, leading to apoptosis. Comparison of the "interactome" of the wild-type and mutant proteins revealed a striking increase in the interaction of the mutant protein with nucleosomal histones ( $\mathrm{H} 2 \mathrm{~A}, \mathrm{H} 2 \mathrm{~B}, \mathrm{H} 3$ and $\mathrm{H} 4)$. Using purified chromatin fractions, we show an increased association of R54CaA-crystallin with these nucleosomal histones, suggesting the potential role of the mutant in transcriptional modulation. Thus, the present study shows that alteration of "interactome" and its nucleosomal association, rather than loss of chaperone activity, is the molecular basis of cataract caused by the R54C mutation in aA-crystallin.

Keywords: aA-crystallin, R54CaA-crystallin, small heat shock proteins (sHSPs), chaperones, cataract. 


\section{Introduction}

$\alpha \mathrm{A}$ - and $\mathrm{aB}$-crystallin are members of the sHsp family and are abundantly present in the mammalian eye lens. They form a large multimeric complex, $\alpha$-crystallin, in the mammalian eye lens, in which the two gene products viz. aA- and aB-crystallin are present in a 3:1 molar ratio $[1,2]$. Both $\alpha \mathrm{A}-$ and $\mathrm{aB}$-crystallin have an oligomeric mass in the range of 600 to $800 \mathrm{kDa}$ with monomer mass of about $20 \mathrm{kDa}$. They may assemble to form homo-oligomers and may form hetero-oligomers with other members [3]. These assemblies are dynamic in nature with a continuous exchange of subunits between the oligomers. These proteins have been demonstrated to exhibit molecular chaperone-like activity and are known to prevent the aggregation of other proteins [4-8], under normal [9-11] and stress conditions [12-15]. They work in an ATP-independent manner and prevent target protein aggregation, thereby keeping them in an active folded state.

The sHSPs are characterized by a well-conserved a-crystallin domain that is flanked by a comparatively less conserved $\mathrm{N}$-terminal domain and a C-terminal extension. The N-terminal domain is known to be important in oligomerization, subunit exchange and chaperone-like activity [16]. Previous studies show that the chaperonelike activity of these proteins can be attributed to various regions spread over the entire length of the sHSP sequence [17]. Studies from our laboratory and others have reported the importance of the N-terminal domain, particularly the SRLFDQFFG stretch, in chaperone-like activity and oligomerization of alpha crystallins [17-19].

Many mutations that cause cataract have been reported in the $\mathrm{N}$-terminal domain of aA-crystallin, both in humans and mice. Interestingly, most of these mutations involve the replacement of the conserved arginine residues at the $12^{\text {th }}, 21^{\text {st }}, 49^{\text {th }}$ and $54^{\text {th }}$ position (figure 1) [20-24]. However, the molecular basis of the mutation-induced cataract formation is not yet well understood. The chaperone-like activity was found to be compromised in several mutations. However, there are a few cases where the chaperone activity seems to be either unaltered or to be increased to some extent [2527]. Therefore, it appears that factors other than the compromised chaperone activity and aggregation propensity also play a deleterious role, which is yet to be understood. For example, the R54C mutation in aA-crystallin leads to congenital cataract [23]. 
However, its chaperone activity is reported to be not altered significantly [25]. We, therefore, verified the structural and chaperone activity alteration, if any, caused by the R54C mutation in a-crystallin. We have investigated the intra-cellular expression/localization and compared the "interactome" of the wild type and mutant aAcrystallin to unravel the molecular basis of the mutation-induced pathology. Interestingly, our study reveals an increased interaction of the mutant with nucleosomal histones. This altered interaction may be a cause of a stress-like response associated with the mutant, leading to cytoskeleton disintegration and apoptosis.

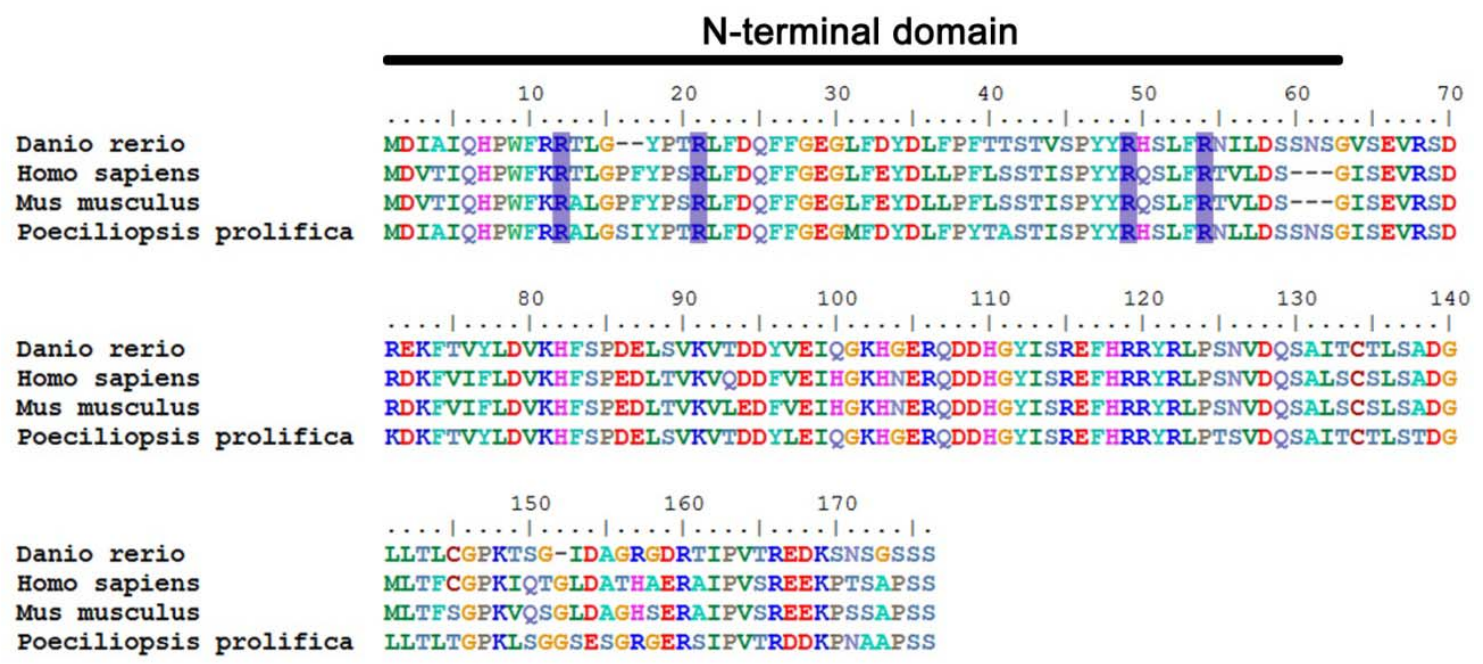

Figure 1: Sequence alignment of $\alpha \mathrm{A}$-crystallin from different species. The alignment reveals the conserved nature of the protein across different phyla. Highlighted in blue are the four well-conserved Arginine residues in the $\mathrm{N}$-terminal domain, mutations in which lead to cataract.

\section{Results}

\subsection{R54C mutation-induced structural alteration of $\alpha A$-crystallin}

To study the effect of the R54C mutation on the structure of human aA-crystallin, we expressed wild type and mutant recombinant proteins in E.coli BL21 (DE3). Like the wild type aA-crystallin, the mutant protein also partitioned exclusively in to the soluble fraction when expressed in the bacterial cells. The wild type and mutant proteins were purified using a method described for the purification of wild type aA-crystallin earlier [6] 
(briefly mentioned in section 2.3).

Far-UV circular dichroism (CD) spectroscopy was performed to compare the secondary structures of the wild type and the mutant protein. As shown in figure 2A, both the mutant (grey curve) and wild type (black curve) protein showed a minimum around $217 \mathrm{~nm}$, indicative of a $\beta$-sheet structure. The mutant R54C, however, showed an increase in the negative ellipticity. A CAPITO (CD Analysis and Plotting Tool) [28] analysis of the CD data indicates an increase in alpha-helical content (table 1). The increased chirality (negative ellipticity) in this region may also be attributed to changes in dihedral angles of certain regions in the mutant sequence [29]. The near-UV CD spectra of mutant and wild type aA-crystallin show marginal changes (figure 2B).

The intrinsic tryptophan fluorescence of the mutant and wild type proteins was studied in an attempt to gain insights into the microenvironment of the tryptophan (9th position) present in aA-crystallin. As the sole tryptophan in aA-crystallin is present in the $\mathrm{N}$-terminal of the protein, it is expected to shed light on the folding of the $\mathrm{N}$-terminal region of the protein. As shown in figure $\mathbf{2 C}$, the tryptophan fluorescence intensity of the mutant was found to be increased slightly compared to the wild type protein, while the emission maximum remained the same $(338 \mathrm{~nm})$.

(A)

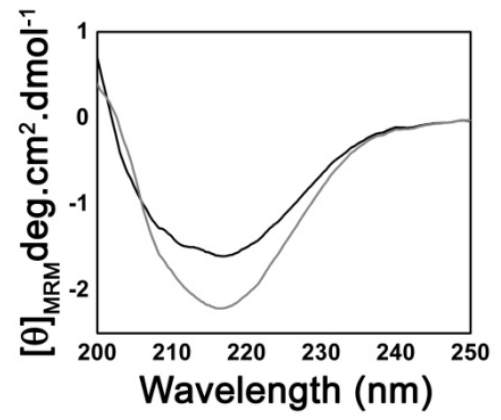

(B)

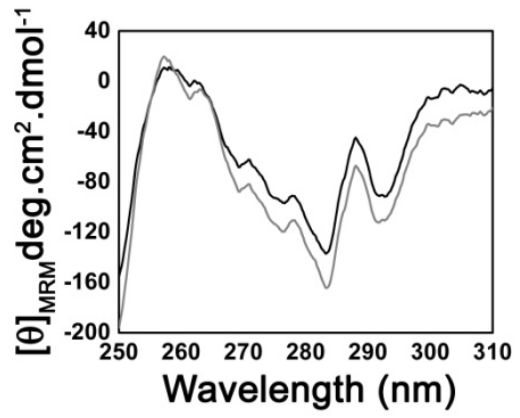

(C)

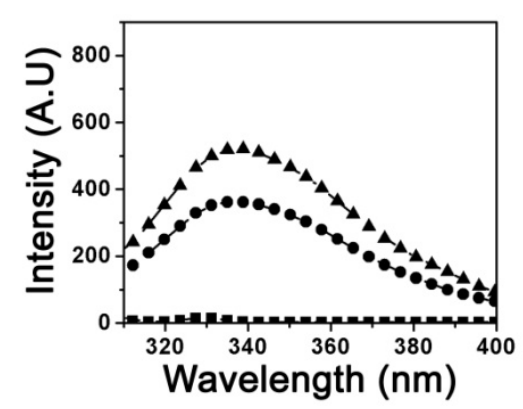

Figure 2: Secondary and tertiary structural studies on the wild type and R54C aA-crystallin. Far-UV CD spectra (A) and near-UV CD spectra (B) of wild type (black line) and R54C mutant (grey line). (C) Tryptophan fluorescence spectra of wild type (black circles) and R54C mutant (black triangles). Baseline buffer fluorescence is shown as black squares. 
Table 1: Percent secondary structure content in wild type and R54C aA-crystallin:

\begin{tabular}{|c|c|c|c|}
\hline aA-crystallin & Helix & $\boldsymbol{\beta}$-strand & Irregular \\
\hline Wild type & 1.9 & 47.2 & 50.9 \\
\hline R54C & 3.7 & 47.7 & 48.6 \\
\hline
\end{tabular}

We investigated the quaternary structure/oligomeric size of the proteins by gel filtration chromatography using a Superose-6 column. Wild type aA-crystallin eluted out at a volume of $14.3 \mathrm{ml}$, whereas the R54C mutant eluted out at a slightly lower elution volume of $13.2 \mathrm{ml}$ (Figure 3). The molecular mass of the wild type and mutant proteins, calculated using their elution volumes, were found to be $540 \mathrm{kDa}$ and $720 \mathrm{kDa}$ respectively. Dynamic light scattering study showed a slightly larger hydrodynamic radius for the mutant $(9.3 \mathrm{~nm})$ as compared to the wild type $(8.7 \mathrm{~nm})$. Overall, our structural studies indicate that the mutant protein exhibits a slightly altered secondary and tertiary structure and assembles into larger oligomers compared to the wild type aA-crystallin.

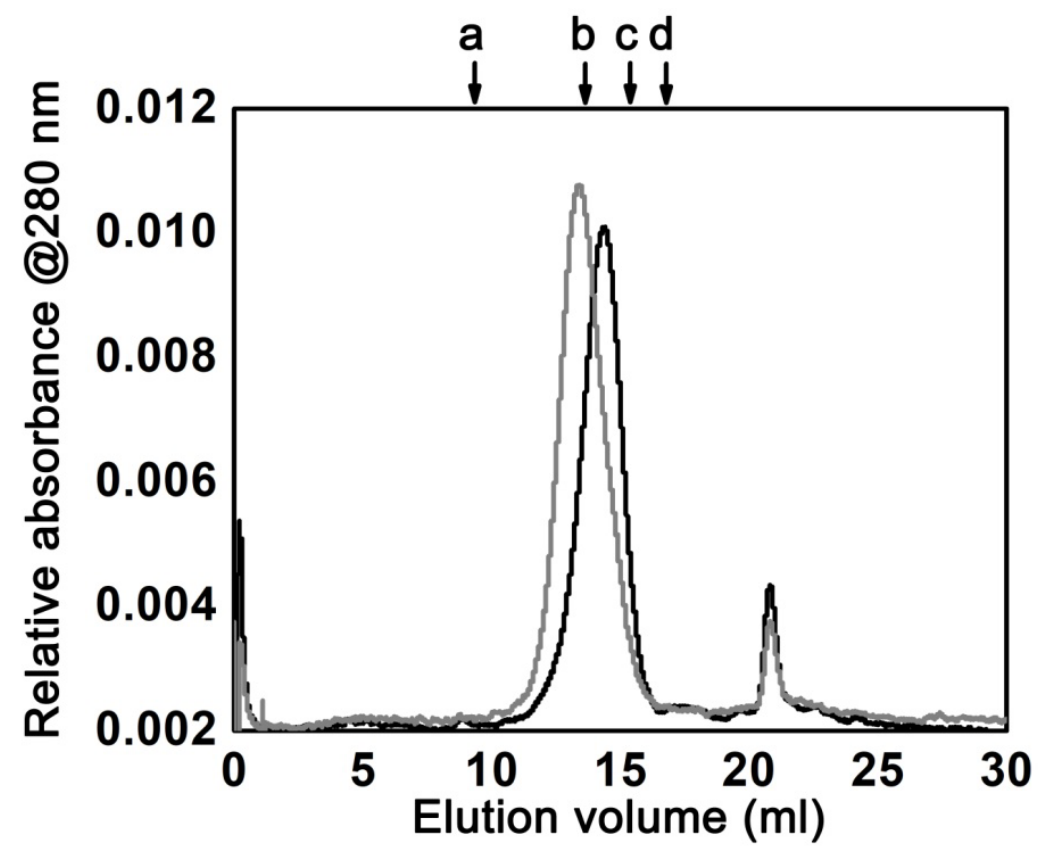


Figure 3: Quaternary structural analysis of wild type and R54C aA-crystallin. Elution profile of wild type (black line) and R54C mutant (grey line), as determined by size-exclusion chromatography. The retention volumes of the molecular mass standards are indicated by the arrows (a, blue dextran $(2000 \mathrm{kDa})$; b, thyroglobulin $(669 \mathrm{kDa}) ; \mathrm{c}$, ferritin $(440 \mathrm{kDa})$; $d$, catalase $(232 \mathrm{kDa}))$. (Note: $\mathrm{y}$-axis is expanded to highlight the difference in the peak positions)

\subsection{Surface hydrophobicity}

We probed the hydrophobic patches on the wild type and mutant aA-crystallin using bis-ANS (a hydrophobic probe). The fluorescence intensity of bis-ANS increases and its emission maximum shifts to lower wavelengths upon binding to hydrophobic surfaces of a protein [30]. In our experiments, the wild type and mutant aA-crystallin did not show any variations in emission maxima of bis-ANS fluorescence. The fluorescence intensity of bis-ANS was found to increase upon binding to wild type as well as R54C aA-crystallin, the increase being slightly higher for the mutant protein compared to that for the wild type protein (figure 4A).

The grand average of hydropathicity (GRAVY) index as determined by the ProtScale prediction suggested an increase in the local hydrophobicity around the substitution site (figure 4B and 4C).

(A)

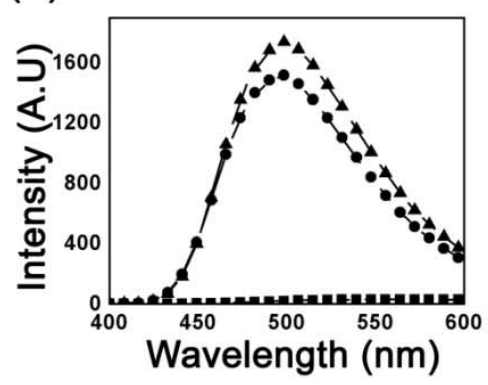

(B)

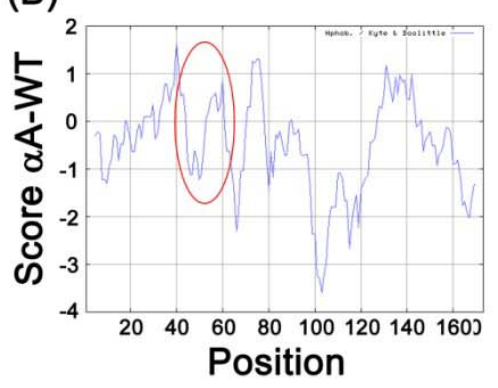

(C)

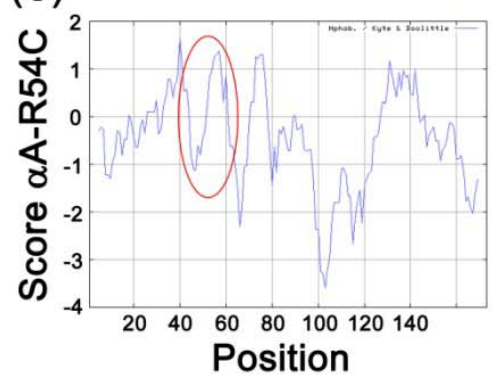

Figure 4: Hydrophobicity analysis of wild type and R54C aA-crystallin. (A) Fluorescence emission by bis-ANS upon binding to wild type aA-crystallin (black circles) and R54C aA-crystallin (black triangles). Black squares represent the emission spectra of bis-ANS in buffer. Grand average of hydropathicity (GRAVY) index as determined by ProtScale prediction for wild type $\alpha A$-crystallin (B) and R54C $\alpha A$-crystallin (C). Red ovals depict the altered hydrophobicity in the region of the mutation $\left(54^{\text {th }}\right.$ amino $\left.\mathrm{acid}\right)$.

\subsection{Intracellular localization of R54C $\alpha A$-crystallin}

The intracellular localization of the R54C mutant and the wild type aA-crystallin was investigated using confocal fluorescence microscopy. As shown in figure 5 (top 
panel), wild type aA-crystallin was mainly localized in the cytoplasm as suggested by a diffused cytoplasmic fluorescence signal. However, as compared to wild type aAcrystallin, the R54C mutant showed a speckled appearance in the nucleus along with a diffused staining in the cytoplasm (figure 5, lower panel).

We also probed the expression and localization of endogenous aB-crystallin in cells over-expressing the mutant and wild type aA-crystallin. The expression of $a \mathrm{~B}$ crystallin in the wild type aA-crystallin-transfected cells was found to be evenly distributed in the cytoplasm and the nucleus. However, in the cells expressing R54C $\alpha A$-crystallin, the expression and localization of $a B$-crystallin was found to be increased in the nucleus (figure 5, lower panel). Profile plots, as generated by imageJ, clearly indicate the enhanced localization of aB-crystallin in the nucleus of the R54C aAcrystallin expressing cells.

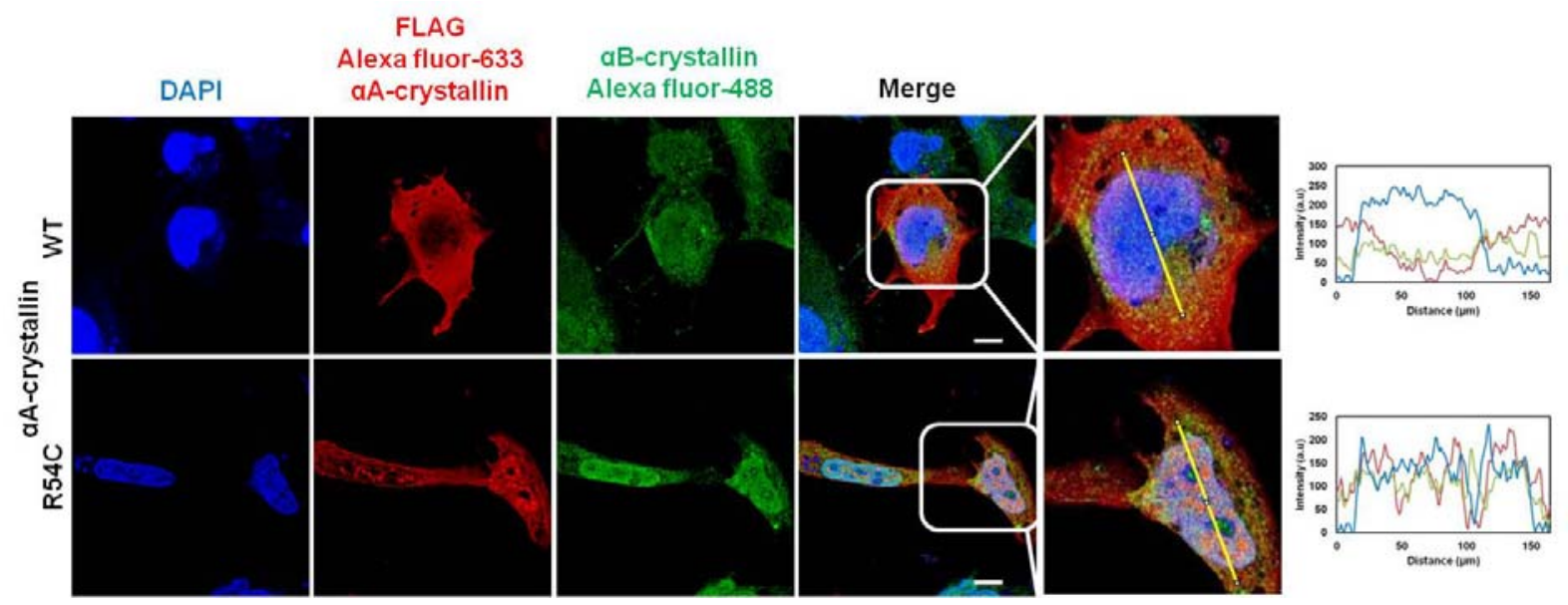

Figure 5: Cellular localization of wild type and R54C aA-crystallin. Confocal fluorescence microscopy of SRA 01/04 cells transfected with pCDNA3.1 vector expressing either wild type aA-crystallin or R54C aA-crystallin (red fluorescence) probed with an anti-FLAG primary antibody followed by a Alexa fluor 633 conjugated secondary antibody. The expression and localization of endogenous aB-crystallin in the transfected cells was probed using immunofluorescence (green fluorescence). (Scale bar = $10 \mu \mathrm{m}$ ). Enlarged image (right panel), of FLAG Alexa fluor633 and aB-crystallin Alexa fluor 488 merge, shows nuclear aggregates of R54C alphaA-crystallin and enhanced aBcrystallin expression in the nucleus. Profile plots for the enlarged merge images were created using ImageJ software, depicting enhanced localization of the mutant R54C aA-crystallin in the nucleus.

\subsection{Comparison of the interactome of R54C $\alpha A$-crystallin and wild type $\alpha A$-crystallin}

Although earlier reports have suggested the presence of wild type aA-crystallin in 
the nucleus [31], the increased nuclear localization of the R54C aA-crystallin mutant led us to investigate the interacting partners of the mutant protein. Point mutations have been shown to alter the interaction between small heat shock proteins and it has been suggested that such alteration could not only lead to absence of the original interaction, but also acquisition of deleterious interactions with new partner(s) [32, 33]. Since the mutant R54C aA-crystallin was found to localize in the nucleus of the SRA 01/04 cells, we probed the intracellular interaction between these proteins by immunoprecipitation using anti-FLAG agarose beads and performed mass spectrometry-based proteomic analysis. A relative intensity-based absolute quantification (iBAQ) of the proteomics results, shown in table $\mathbf{2}$, revealed major differences in the interacting partners of the wild type and mutant $\alpha A-$ crystallin.

Table 2: Interacting partners of wild type and R54C aA-crystallin:

\begin{tabular}{|c|c|c|c|c|c|}
\hline & INTERACTING PARTNERS & $\begin{array}{c}\text { ALPHA A } \\
\text { WT (IBAQ) }\end{array}$ & $\begin{array}{c}\text { STANDARD } \\
\text { DEVIATION }\end{array}$ & $\begin{array}{c}\text { ALPHA A } \\
\text { R54C (IBAQ) }\end{array}$ & $\begin{array}{c}\text { STANDARD } \\
\text { DEVIATION }\end{array}$ \\
\hline 1 & Alpha-crystallin A & 71.82 & 4.40 & 35.49 & 6.40 \\
\hline 2 & HSP27 & 4.14 & 0.95 & 3.60 & 1.26 \\
\hline & HISTONES & & & \\
\hline 3 & Histone H2A & 1.11 & 0.35 & 6.18 & 2.13 \\
\hline 5 & Histone H2B & 0.62 & 0.29 & 4.76 & 3.41 \\
\hline 6 & Histone H3 & 0.09 & 0.16 & 0.96 & 1.66 \\
\hline & Histone H4 & 1.86 & 0.08 & 11.50 & 8.05 \\
\hline 7 & UBIQUITINYLATION & & & & 0.06 \\
\hline 8 & E3 ubiquitin-protein ligase AMFR & 2.96 & 1.10 & 9.26 & 6.86 \\
\hline & CYTOSKELETAL ELEMENTS & & & & \\
\hline 9 & Alpha Tubulin & 0.17 & 0.07 & 0.36 & 0.09 \\
\hline 10 & Vimentin & 2.12 & 0.26 & 2.59 & 0.93 \\
\hline 11 & Collagen alpha-1(I) chain & 0.00 & 0.00 & 0.01 & 0.01 \\
\hline & TRANSCRIPTION FACTORS & & & & \\
\hline 12 & rRNA 2-O-methyltransferase & 0.03 & 0.01 & 0.08 & 0.08 \\
\hline 13 & fibrillarin & 2.58 & 4.46 & 0.00 & 0.00 \\
\hline 14 & HATA-binding protein-associated & 0.00 & 0.00 & 0.04 & 0.07 \\
\hline 15 & fucleoside diphosphate kinase & 0.14 & 0.10 & 0.45 & 0.31 \\
\hline 16 & 60S ribosomal protein L8 & 0.00 & 0.00 & 0.18 & 0.32 \\
\hline 17 & Elongation factor 1-alpha 1 & 0.40 & 0.31 & 0.23 & 0.04 \\
\hline 18 & Chromodomain-helicase-DNA- & 0.00 & 0.00 & 0.04 & 0.06 \\
\hline & $\quad$ & & & 0.06 & \\
\hline
\end{tabular}




\begin{tabular}{|c|c|c|c|c|c|}
\hline & binding protein 3 & & & \\
\hline & MISCELLANEOUS & & & \\
\hline 19 & Alpha-synuclein & 3.18 & 4.11 & 0.30 & 0.27 \\
\hline 20 & $\begin{array}{c}\text { Glyceraldehyde-3-phosphate } \\
\text { dehydrogenase }\end{array}$ & 0.11 & 0.02 & 0.37 & 0.20 \\
\hline 21 & $\begin{array}{c}\text { CAS1 domain-containing protein } \\
1\end{array}$ & 0.04 & 0.07 & 0.00 & 0.00 \\
\hline 22 & $\begin{array}{c}\text { Enhancer of rudimentary } \\
\text { homolog }\end{array}$ & 0.77 & 0.56 & 2.23 & 1.47 \\
\hline 23 & Protein LSM14 homolog A & 0.02 & 0.00 & 0.09 & 0.01 \\
\hline 24 & Protein S100-A9 & 0.60 & 0.11 & 1.68 & 0.93 \\
\hline 25 & Junction plakoglobin & 0.06 & 0.02 & 0.21 & 0.13 \\
\hline 26 & Desmoplakin & 0.05 & 0.02 & 0.17 & 0.10 \\
\hline 27 & Dermcidin & 6.63 & 1.76 & 15.66 & 8.66 \\
\hline 28 & $\begin{array}{c}\text { Heterogeneous nuclear } \\
\text { ribonucleoprotein U }\end{array}$ & 0.13 & 0.03 & 1.07 & 0.83 \\
\hline 29 & Desmoglein-1 & 0.15 & 0.03 & 0.47 & 0.26 \\
\hline 30 & $\begin{array}{c}\text { Uncharacterized protein } \\
\text { C15orf52 }\end{array}$ & 0.00 & 0.00 & 0.06 & 0.10 \\
\hline 31 & $\begin{array}{c}\text { Plasminogen activator inhibitor } \\
\text { 1 RNA-binding protein }\end{array}$ & 0.02 & 0.02 & 0.14 & 0.02 \\
\hline 32 & Progesterone receptor & 0.00 & 0.00 & 0.79 & 1.36 \\
\hline 33 & Lysozyme C & 0.08 & 0.15 & 0.68 & 0.62 \\
\hline
\end{tabular}

Major differences were found to be in relative concentrations of histones, ubiquitinylation-related proteins and intercellular interaction proteins. The histones identified with an increased concentration upon immunoprecipitation with the mutant protein were $\mathrm{H} 2 \mathrm{~A}, \mathrm{H} 2 \mathrm{~B}, \mathrm{H} 3$ and $\mathrm{H} 4$, which interestingly constitute the nucleosome (figure 6). Other major variations were found in ubiquitinylation-related proteins and desmosomal proteins involved in cell-cell adhesion. 


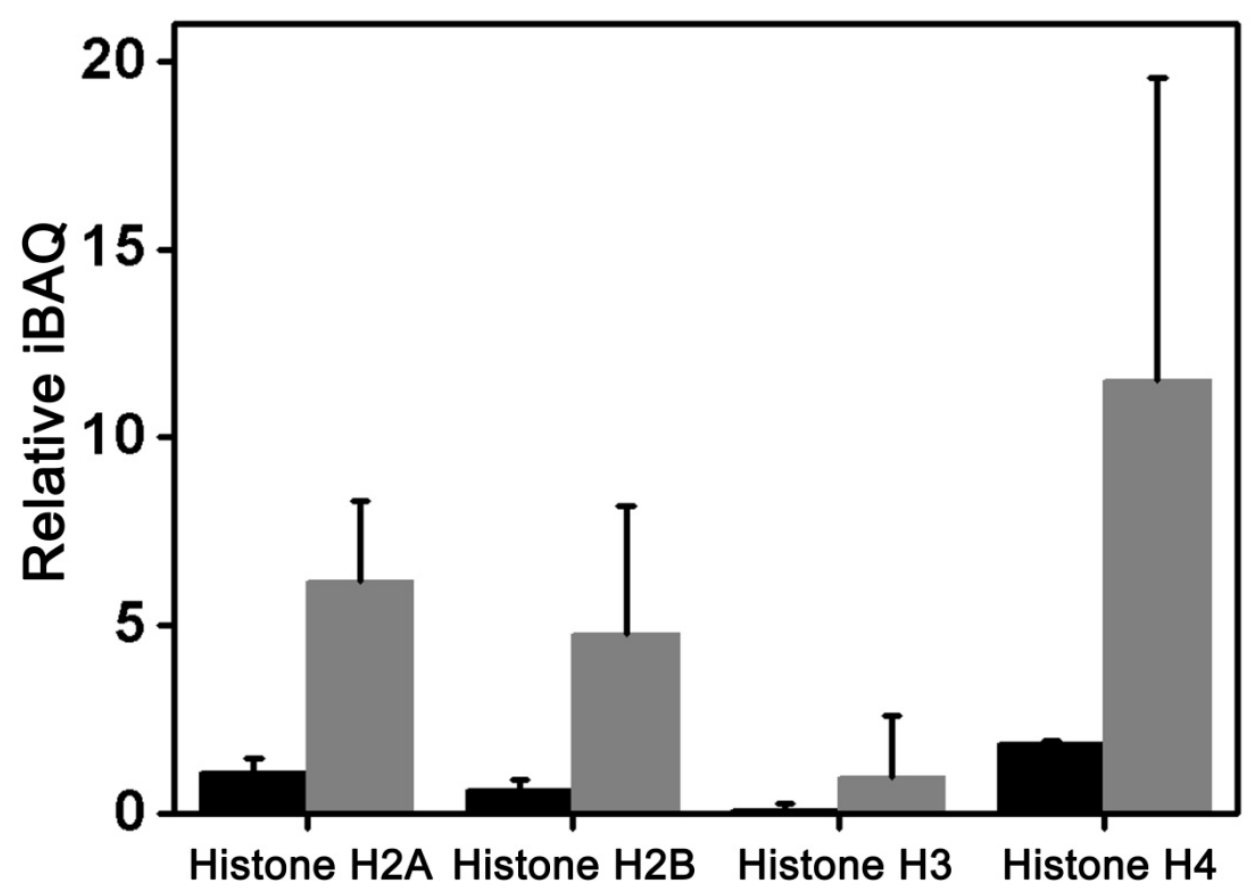

Figure 6: Histone binding to wild type and $\alpha A$-crystallin. Relative $i B A Q$ concentrations of different histones found to interact with wild type (black bars) and mutant R54C (grey bars) aA-crystallin as determined by immunoprecipitation followed by intensity based absolute quantification (iBAQ).

\subsection{Intra-nuclear localization of wild type and R54C aA-crystallin}

The proteomic study revealed an increased association of the mutant protein with histones. This association could be either with the nucleosome/chromatin or with the soluble pool of histones or both. We investigated whether the association of the mutant protein is with nucleosome/chromatin. We performed chromatin enrichment followed by western blotting to elucidate the binding of the mutant with DNA chromatin-associated histones. As shown in figure 7, the association of the mutant $a A$-crystallin was found to be increased with the chromatin fraction as compared to the wild type protein. The interaction of the mutant with the histones was further investigated by an immunofluorescence experiment. When probed using anti-histone $\mathrm{H} 3$ antibody, the mutant crystallin was found to co-localize with histone $\mathrm{H} 3$ (figure 8). Our 
immunofluorescence and western blotting of the chromatin-enriched fractions suggest that the mutant protein is a part of the nucleosome complex and interacts with all four histone proteins of the nucleosome complex.

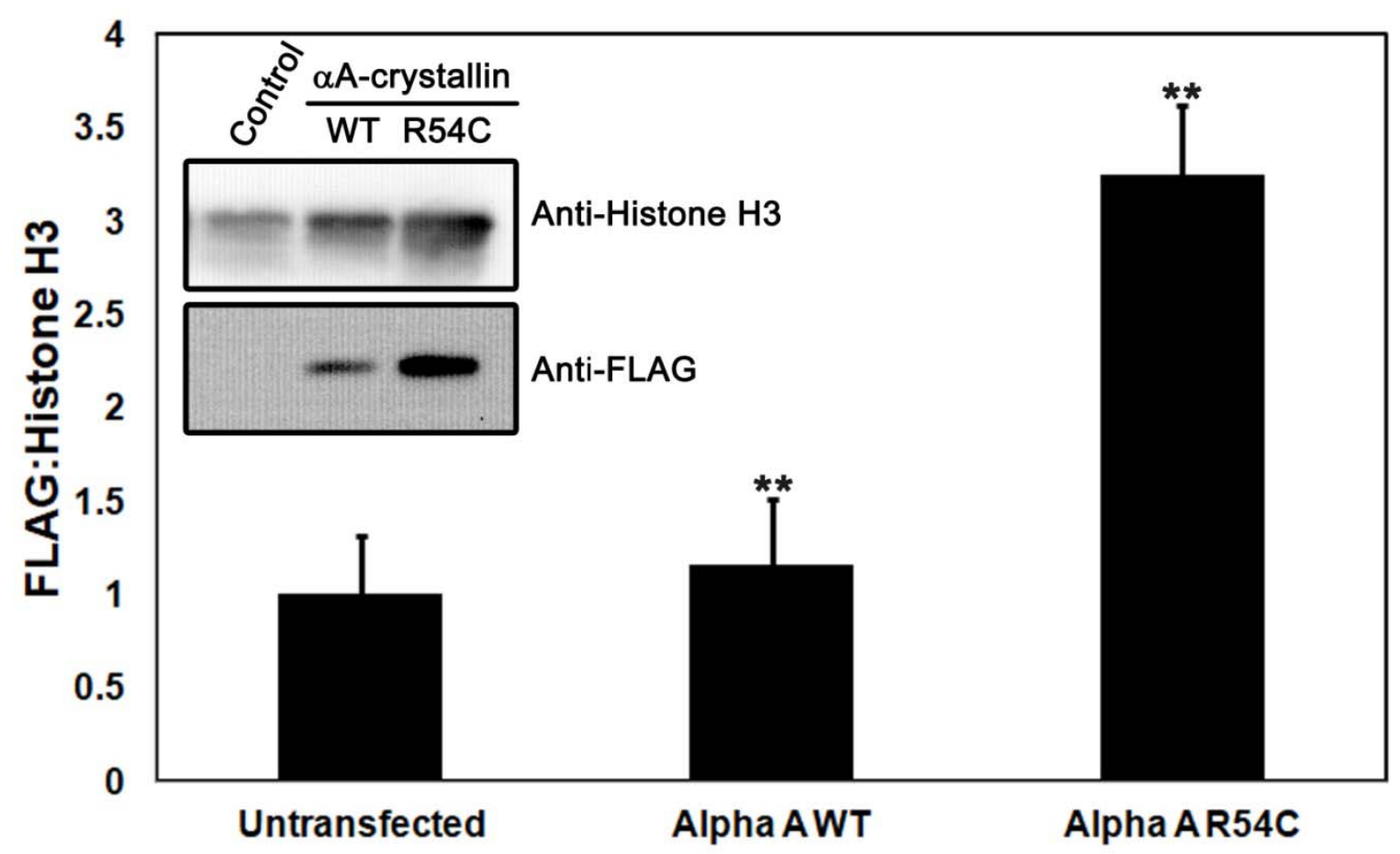

Figure 7: Interaction of wild type and R54C aA-crystallin with chromatin. Chromatin fractions from control cells and cells expressing wild type aA-crystallin and R54C aA-crystallin were isolated. The samples were processed and subjected to polyacrylamide gel electrophoresis as described in the materials and methods. Western blot image in the inset shows an increased level of R54C aA-crystallin in the chromatin enriched fraction as compared to that of wild type aA-crystallin. Image quantification was performed using imageJ. Bar graph represents the ratio of FLAG to Histone H3 for each group. Band intensities for FLAG:Histone H3 in the untransfected samples were normalized to 1. $\left(n=3 ;{ }^{* *} p<0.01 ;\right.$ two-tailed Welch's t-test). 


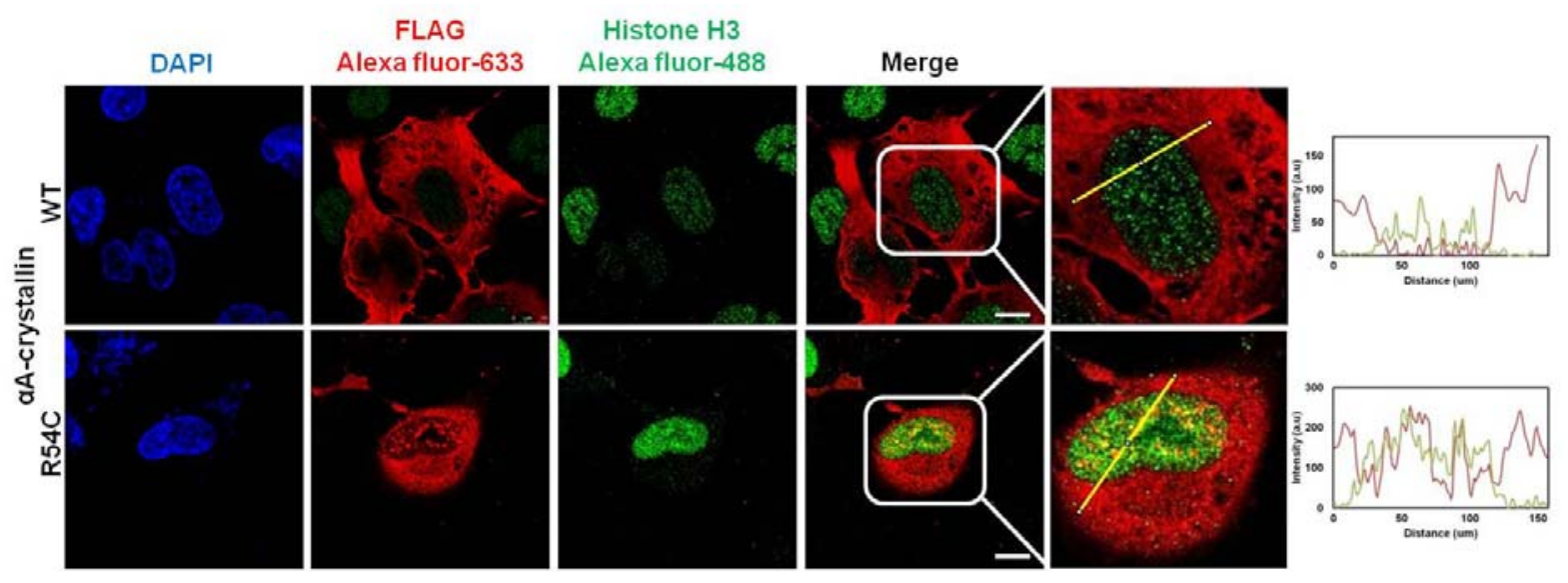

Figure 8: Interaction of wild type and R54C aA-crystallin with chromatin. Confocal fluorescence microscopy of SRA 01/04 cells transfected with pCDNA3.1 vector expressing either WT aA-crystallin or R54C aA-crystallin (red fluorescence) probed with an anti-FLAG primary antibody followed by Alexa fluor 633 conjugated secondary antibody. The expression and localization of histone $\mathrm{H} 3$ was probed using anti-histone $\mathrm{H} 3$ antibody followed by staining with Alexa fluor 488 (green fluorescence). (Scale bar $=10 \mu \mathrm{m}$ ). Enlarged image (right panel) of the merge of FLAG Alexa fluor-633 and Histone H3 Alexa fluor 488 shows yellow fluorescence in the case of R54C aA-crystallin but not in wildtype aA-crystallin, indicating colocalization. Profile plots for the enlarged merge images were created using ImageJ software, depicting co-localization of the mutant R54C aA-crystallin with Histone H3.

\subsection{Effect of R54C $\alpha A$-crystallin expression on cytoskeletal elements}

The effect of expression of the R54C mutant and wild type aA-crystallin in SRA 01/04 cells on the organisation of cytoskeletal elements was studied using confocal fluorescence microscopy. As shown in figure 9A and B (top panel), expression of wild type aA-crystallin had no particular effect on the organisation of actin and tubulin structure. However, as compared to the wild type aA-crystallin, the expression of the mutant R54C led to a depolymerisation of the actin and tubulin filaments figure $9 \mathrm{~A}$ and B (lower panel). 


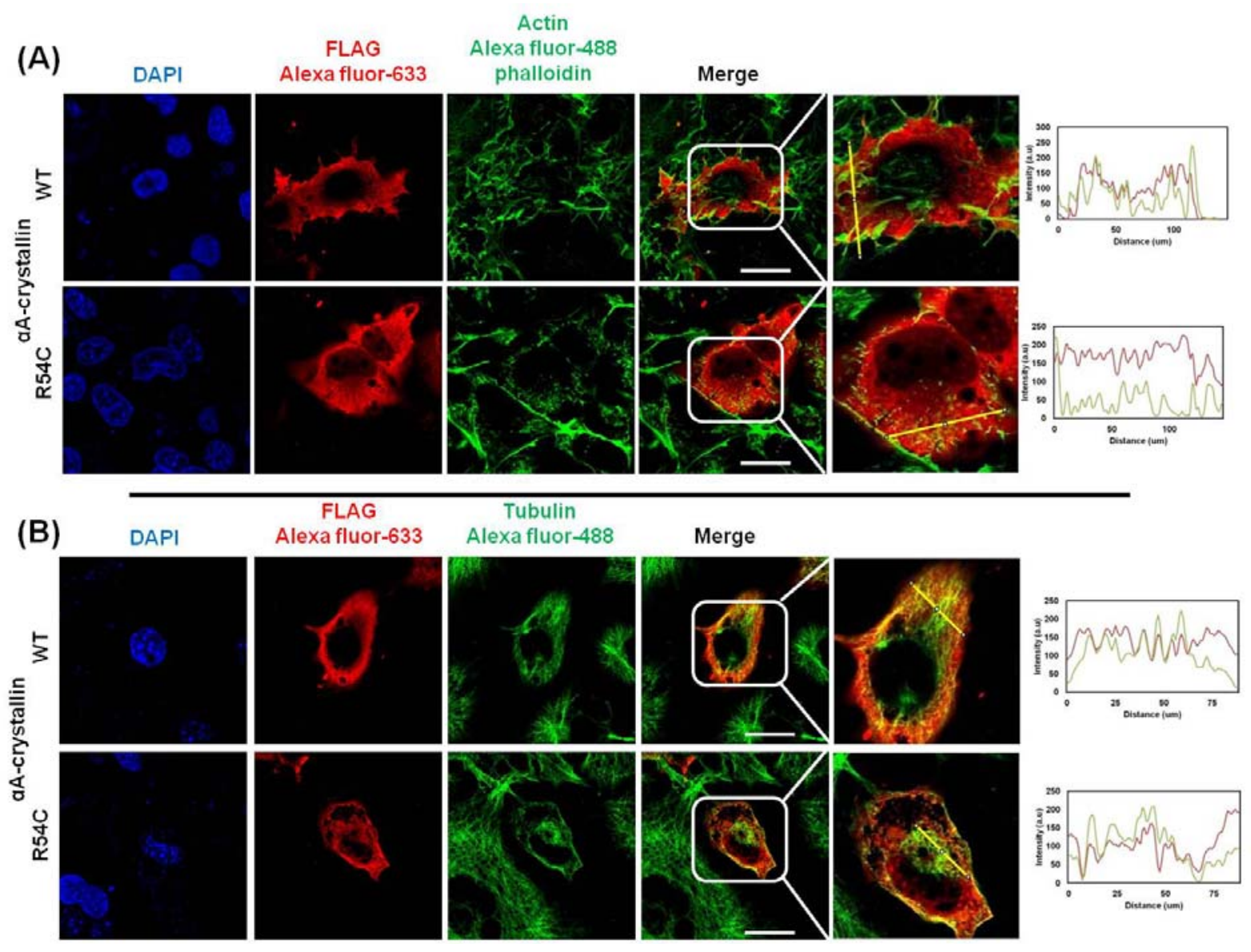

Figure 9: Interaction of wild type and R54C aA-crystallin with cytoskeletal elements. Confocal fluorescence microscopy of SRA 01/04 cells transfected with PCDNA3.1 vector expressing either wild type aA-crystallin or R54C aA-crystallin (red fluorescence) probed with an anti-FLAG primary antibody followed by Alexa fluor 633 conjugated secondary antibody. (A) The expression and localization of endogenous actin in the transfected cells was probed using Alexa fluor 488 phalloidin (green fluorescence). Profile plots for the enlarged merge images were created using Image J software, depicting co-localization of the wild type aA-crystallin with actin. There was minimal co-localization of the R54C aA-crystallin with actin and the actin intensity was in general low, suggesting depolymerisation of actin filaments. (B) The expression and localization of endogenous tubulin in the transfected cells was probed with an antitubulin primary antibody followed by Alexa fluor 488 conjugated secondary antibody (green fluorescence). Profile plots for the enlarged merge images were created using ImageJ software, depicting co-localization of the wild type and mutant R54C aA-crystallin with tubulin (Scale bar $=25 \mu \mathrm{m}$ ). Enlarged image (right panel) of the merge shows the filamentous actin Alexa fluor-488 phalloidin (9A), and tubulin Alexa fluor-488 staining (9B) for wild type alpha Acrystallin transfected cells, which is not seen in the mutant R54C alphaA-crystallin transfected cells, suggesting a stress-like response.

\subsection{Cell death associated with $R 54 C$ aA-crystallin}

The effect of the expression of the mutant R54C aA-crystallin on SRA 01/04 cell 
survival was studied by MTT assay. The transfection efficiency of the cells was low $(30 \%)$ and the selection of these cells using geneticin to create a stable transfectant pool was not possible due to cell death. MTT assay results, as shown in figure 10A, revealed cell death in mock-transfected cells ( 34.5\%) as well as in wild type aAcrystallin-transfected cells (32.85\%). This could be due to the effect of the transfection reagent, lipofectamine, on the cells. Interestingly, in cells transfected with R54C aAcrystallin, cell death was found to be $\sim 57.21 \%$. Considering the fact that the transfection efficiency was as low as 30\%, the cell death in cells transfected with R54C aA-crystallin is significantly higher than that observed in mock-transfected cells and wild type aAcrystallin-transfected cells. Further, in order to probe the mechanism of cell death, we have studied Caspase 3 activation in cells transfected with the mutant and wild type aAcrystallin. As shown in figure 10B, Caspase 3 was found to be activated/fragmented in cells transfected with R54C aA-crystallin. On the other hand, activation of caspase 3 was not observed in mock-transfected cells and cells transfected with wild type aAcrystallin.

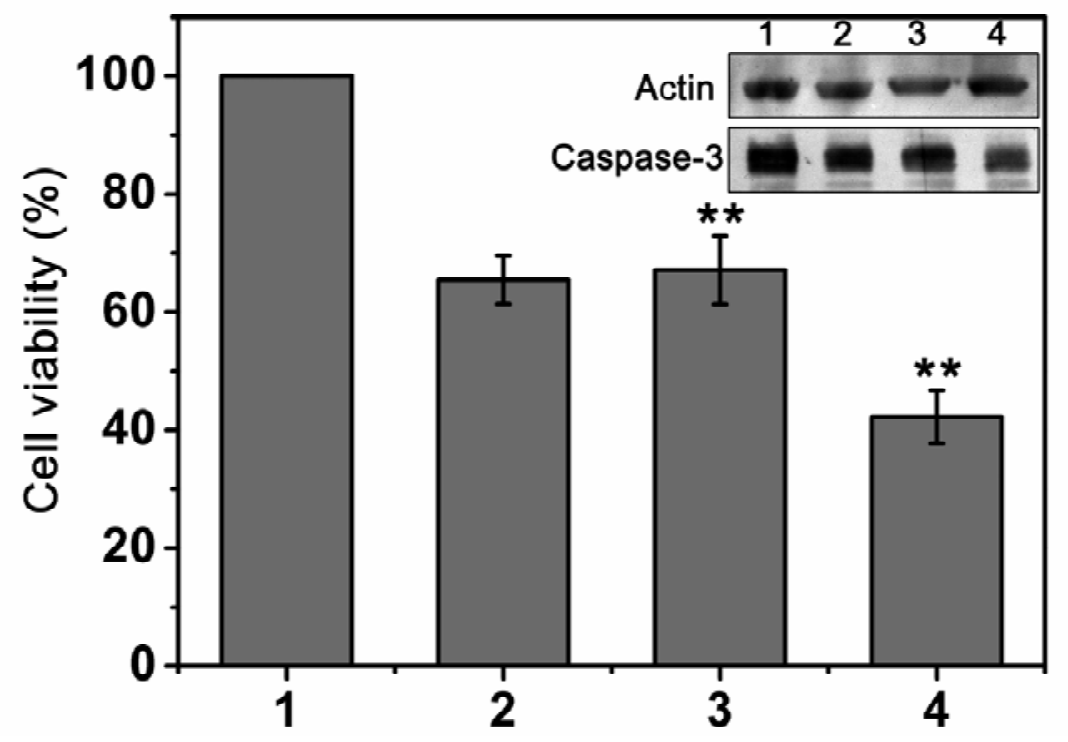

Figure 10: Cytotoxicity of wild type and R54C aA-crystallin. (A) MTT assay for the quantification of cell death associated with the expression of R54C aA-crystallin ( $n=3$; ${ }^{* *} p<0.01$; two-tailed Welch's t-test). Inset shows decrease in the expression of pr-caspase- 3 in cells transfected with R54C aA-crystallin suggesting apoptosis (1: Untransfected cells, 2: Cells transfected with empty vector; 3; Cells transfected with wild type aA-crystallin and 4: Cells transfected with R54C aA-crystallin). (Arrow indicates fragmented caspase 3 band prominent in the mutant 
R54C aA-crystallin transfected cells).

\section{Discussion}

a-Crystallin is known to be involved in various cellular functions [33, 34]. The primary structure of the protein comprises of three domains viz. the N-terminal domain, a-crystallin domain and the C-terminal extension. Various studies have suggested the role of the $\mathrm{N}$-terminal in sub-unit exchange, oligomerization and chaperone-like activity $[16,18]$. Many mutations in aA-crystallin have been reported to cause cataract. Interestingly, mutations in all the conserved arginine residues (R12, R21, R49 and R54) in the $\mathrm{N}$-terminal domain of the protein have been reported to cause cataract. Understanding the mechanism of cataract caused by these mutations thus becomes important.

In an attempt to gain an insight into the structural variations caused by R54C mutation in aA-crystallin, we cloned, expressed and purified the mutant R54C aAcrystallin protein and compared its structure and chaperone-like activity with wild type aA-crystallin. Our results show slight secondary and tertiary structural differences of the mutant as compared to wild type aA-crystallin. The mutant also showed an increase in the oligomer size, hydrodynamic radius and an increase in the surface hydrophobicity.

Several point mutations in $\mathrm{aA}$ - and $\mathrm{aB}$-crystallin are known to result in the loss of chaperone-like activity, thereby causing cataract. Mutation of F71 and R116 in aAcrystallin and R120 in aB-crystallin has been shown to severely compromise the chaperone-like activity of these proteins [25, 35-37]. The G98R mutation in aA-crystallin showed a substrate-specific chaperone-like activity. While the chaperone-like activity was severely compromised for DTT-induced insulin aggregation [36], the activity was found to be slightly compromised for thermal aggregation of alcohol dehydrogenase, ovotransferrin and $\beta B 2-c r y s t a l l i n$ [38]. Interestingly, an intact or enhanced chaperonelike activity was observed against the thermal aggregation of citrate synthase [38, 39]. On the other hand, no major changes have been reported in the chaperone-like activity of the R49 and R54 mutants of aA-crystallin [25, 26]. Still other mutations viz. Y118 in aA-crystallin [27] and R11 [40], Q151, 450DelA and 464DelCT [41] in aB-crystallin have been reported to have an improved chaperone-like activity compared to the wild type 
protein. Despite the minor structural variations observed for the mutant R54C $\mathrm{AA}$ crystallin, the chaperone-like activity of the mutant and wild type aA-crystallin was found to be comparable when studied against DTT-induced insulin aggregation and temperature-induced ADH aggregation (data not shown). These results are in conformity with those shown earlier for the R54C mutant of aA-crystallin [25]. Thus, factors in addition to mutational effects on the general chaperone activity of a-crystallin also seem to play a critical role in the pathology. However, these factors have not been adequately studied so far.

To gain further insights into the mechanistic details of the cataract caused by the R54C mutation, we expressed the mutant and wild type proteins in human lens epithelial cells (SRA 01/04). Immuno-fluorescence studies show that the expression of the wild type aA-crystallin is diffused across the cytoplasm. Whereas, the R54C mutant protein is seen as speckles, both in the cytoplasm and in the nucleus suggesting protein translocation and aggregation. A similar observation has been reported by Mackay et al. in the case of R49C aA-crystallin transfected cells [24]. The expression of mutant aAcrystallin affects the localization of aB-crystallin as well. In the cells expressing wild type aA-crystallin, the expression of aB-crystallin is seen to be evenly distributed both in the cytoplasm and in the nucleus. Whereas, in the cells expressing the R54C aA-crystallin, the localization is altered; there is considerably more aB-crystallin in the nucleus of these cells. Mackay et al. [24] have shown that R49CaA-crystallin aggregates and translocates to the nucleus. They suggested that since aB-crystallin forms a heteromeric complex with R49C aA-crystallin, aB-crystallin is also found to be translocated to the nucleus. It is possible that the translocation of aB-crystallin to the nucleus observed by us in the present study is also due to its hetero-oligomer formation with the R54C mutant, which aggregates and translocates to the nucleus in a manner similar to that observed in the case of the R49C mutant. However, aB-crystallin is also known to translocate into the nuclei of the cells under stress [42]. The expression of mutant proteins, its aggregation and translocation into the nucleus also cause stress to the cell, leading to stress-induced translocation of aB-crystallin into the nucleus, independent of hetero-oligomer formation with aA-crystallin. The latter explanation seems to be more reasonable as we could not identify aB-crystallin in our 
immunoprecipitation results (table 3). Raju et al. have reported a speckled appearance of R54C aA-crystallin in the cytoplasm of HeLa cells [43]. Cytoplasmic aggregation of mutant a-crystallin proteins has also been previously reported. However, such aggregations in all cases except the R49C mutant of aA-crystallin have been shown to be cytoplasmic. The mutant reported in the present study viz. R54C aA-crystallin, is only the second such report of a mutant aggregating and localizing in the nucleus.

To gain insights into the difference in functioning of the wild type and mutant proteins we studied the "interactome" of the two proteins. The results of the proteomic study reveal a striking increase ( 10 fold) in the concentration of histones interacting with the mutant as compared to the wild type. The major histones identified in the immunoprecipitation experiments were $\mathrm{H} 2 \mathrm{~A}, \mathrm{H} 2 \mathrm{~B}, \mathrm{H} 3$ and $\mathrm{H} 4$; histones constituting the nucleosome [44]. Isolation and probing chromatin enriched fractions for the wild type and mutant proteins demonstrated an increased association of the R54C aA-crystallin with chromatin-enriched fractions, further confirming the association with the nucleosome. Histones are important proteins with a long half-life. Their association with wild type aA-crystallin has also been observed previously [32, 45], suggesting a possibility of protection of histones by crystallins in maintaining their cellular functions. More recently a direct interaction of aA-crystallins with histones was reported by Hamilton and Andley [46]. It was suggested that histones interact with crystallins and leads to alterations in the oligomeric status of the crystallin protein. The oligomeric changes, however, depend on the histone to crystallin ratio with a low histone to crystallin ratio resulting in water-soluble complexes while a high histone to crystallin leads to water-insoluble complexes. A further increase in histone to crystallin ratios results in the formation of both water soluble and insoluble complexes. An increase in the abundance of histones has also been reported in $\alpha \mathrm{A} / \mathrm{aB}$ double knock-out mice lenses and in lens cells expressing aA-crystallin mutants [32], probably due to an effort on the part of cells to maintain a functional pool of histones for normal cellular activities. The accumulation of histone transcripts has also been shown in lens epithelial cells upon stress viz. irradiation with ultraviolet C radiation waves [47]. In the study by Hamilton and Andley [46], it was speculated that the nuclear aggregation of the R49C aA-crystallin protein is a direct consequence of the increased histone to aA-crystallin 
ratio, resulting in water-insoluble complexes. This aggregation may sequester the histones, preventing their binding to the chromatin. In our study we show that although the mutant R54C aA-crystallin interacts with histones, the histones + R54C aA-crystallin complex still bound to chromatin. The exact consequence of this interaction still needs to be elucidated, but this may lead to an alteration in the trasncriptomic profiles, as observed in mouse lenses expressing R49CaA-crystallin [48].

The R54C mutation in aA-crystallin leads to recessive cataracts in humans. Interestingly, histones have been shown to play an important role in the regulation of Wnt signalling pathway, which is known to be important in lens development and morphogenesis and has been linked with cataract formation in different model systems $[49,50]$. It can thus be speculated that the increased association of the mutant $\alpha A$ crystallin with nucleosomal histones, may modulate cellular transcriptional activity including that mediated by $\beta$-catenin thereby affecting the Wnt signalling pathway. This may be a possible reason for improper lens development and cataract formation in the mutant lenses [51]. Our findings show increased interaction of various junction proteins viz. plakoglobin, desmoplakin and desmoglein in the lens epithelial cells. Cadherinbased junctions are important features of undifferentiated lens epithelial cells and aid in the organization of cytoskeletal elements during lens development [52]. A sequestration of these proteins by the mutant protein may thus lead to impairment in lens fibre formation and development.

a-Crystallin is known to interact with a variety of client proteins and stabilize them [33]. The role of chaperoning and stabilizing actin and tubulin by aB-crystallin has been well established [53,54]. Also, the expression of aB-crystallin is known to increase in the presence of microtubule-destabilizing drugs, confirming its role in microtubule assembly [55]. Both $\alpha \mathrm{A}$-crystallin and actin have been shown to be important for the proper development of the lens. Further, mutant R116C aA-crystallin has been shown to exhibit decreased interaction with actin compared to wild type aA-crystallin. It has therefore been suggested that decreased interaction of mutant $\alpha A$-crystallin may disturb the normal differentiation process, causing lens opacity [56]. Our work for the first time reports the destabilising nature of a mutation in aA-crystallin on the cytoskeletal elements. However, the destabilization of microtubule assembly observed with the over- 
expression of the R54C aA-crystallin could also be due to lack of sufficient aB-crystallin in the cytosolic compartment of the cell, due to its translocation in the nucleus.

a-Crystallins along with other sHSPs have been reported to prevent apoptosis induced by a variety of factors viz. oxidative stress, staurosporine, TNF-a, etc [57-59] and may exhibit this anti-apoptotic effect through various ways. For instance, $a \mathrm{~B}-$ crystallin translocates to the mitochondria during oxidative stress and protects mitochondrial membrane potential [60]. Both $\alpha \mathrm{A}-$ and $\mathrm{aB}$-crystallin bind to Bax and Bcl$\mathrm{X}(\mathrm{S})$ (pro-apoptotic molecules) and prevent their translocation to the mitochondria [61]. They are also known to suppress the activation of caspase 6 and caspase 3 and prevent apoptosis [62]. Mutations in a-crystallins are known to reduce its anti-apoptotic activity, and may even lead to induction of apoptosis [24,63]. The activation of caspase 3 and induction of apoptosis observed in the present study in R54C aA-crystallintransfected cells could be due to induction of apoptosis by the mutant protein and also its inability to bind and inhibit activation of caspase 3.

To summarize, the R54C mutation in aA-crystallin does not result in a significant loss of structure or chaperone activity of the aA-crystallin protein. It, however, leads to aggregation and nuclear translocation of the protein when expressed in cell culture. An altered interactome of the mutant and its association with nucleosome triggers a stresslike response, which results in a cascade of events including translocation of $a \mathrm{~B}$ crystallin to the nucleus, depolymerisation of the cytoskeletal elements and eventual cell death. This seems to be the plausible molecular mechanism underlying the mutationinduced cataract formation. As various neurodegenerative diseases (such as aggregate formation by polyglutamine (polyQ)) [64] and cataract [65] are characterized by the formation of nuclear inclusions of abnormal proteins, our study may also shed light on the possible mechanism of stress and cell death caused by such nuclear inclusions.

\section{Materials and Methods}

\subsection{Materials}

pET-21a (+) vector, T7 promoter and T7 terminator primers were obtained from 
Novagen (Madison, WI). pcDNA3.1 was obtained from Addgene (Cambridge, MA). Mutagenic primers and aA-crystallin-specific primers with restriction sites were obtained from Bioserve. Gel filtration chromatographic medium Bio-Gel A-1.5m was purchased from Bio-Rad Laboratories (Hercules, CA). Q-Sepharose matrix, Superose-6 HR 10/30 column and high molecular weight protein calibration kit comprising of blue dextran (2000 kDa), thyroglobulin (669 kDa), ferritin (440 kDa) and catalase (232 kDa) were purchased from Amersham Biosciences (Uppsala, Sweden). Insulin, dithiothreitol (DTT), Alcohol dehydrogenase (ADH), Anti-FLAG antibody and Anti-FLAG antibodyconjugated agarose beads were obtained from Sigma (St. Louis, MO). 1,1'-bi(4-anilino) naphthalenesulfonic acid (Bis-ANS) and Alexa Fluor ${ }^{\circledR} 488$ phalloidin were purchased from Thermo Fisher Scientific (Waltham, MA, USA). Antibodies against aB-crystallin, caspase 3 and actin were obtained from Abcam (Cambridge, UK). Alexa Fluor 488 and Alexa Fluor 633 conjugated secondary antibodies were obtained from Thermo Fisher Scientific (Waltham, MA, USA). HRP-conjugated secondary anti-rabbit and anti-mouse IgG antibodies were obtained from PerkinElmer (Waltham, MA, USA). Vectashield antifade mounting medium with 4',6-diamidino-2-phenylindole (DAPI) was obtained from Vector Laboratories (Burlingame, CA, USA). 3-(4,5-dimethylthiazol-2-yl)-2,5diphenyltetrazolium bromide (MTT) reagent was obtained from Calbiochem (San Diego, CA, USA).

\subsection{Creating R54C mutant of $\alpha A$-crystallin}

pET-21a $(+)$ vector with recombinant human aA-crystallin gene cloned between Ndel and Hindlll restriction sites was used as a template to generate the R54C mutant. Briefly, the mutant was generated by mutating the $54^{\text {th }}$ codon, CGC to TGC, using polymerase chain reaction (PCR). Two independent polymerase chain reactions (PCRs) were performed using i) a forward T7 promoter primer and the mutagenic primer 5'CAG CAC GGT GCT GAA GAG GGA C-3' as the reverse primer, ii) the mutagenic primer 5'- G TCC CTC TTC TGC ACC GTG CTG-3' as the forward primer and T7 terminator primer as the reverse primer. The resulting partially overlapping fragments were reamplified using $\mathrm{T} 7$ promoter and $\mathrm{T} 7$ terminator primers. The amplified fragment was digested and ligated in the Ndel and Hindlll sites of the pET-21a(+) expression 
vector. The sequence of the construct was verified by T7 promoter and T7 terminator primers using $3700 \mathrm{ABI}$ automated DNA sequencer.

For cloning the respective genes in mammalian expression vector, pcDNA3.1, the gene sequence of the wild type and the mutant protein were amplified using PCR with primers specific for aA-crystallin having restriction sites EcoRI and Xhol (forward primer 5'-CCG GAA TTC ATG GAC GTG ACC ATC CAG-3' and reverse primer 5'-CCG CTC GAG TTA GGA CGA GGG AG-3'). The amplified fragment was digested and ligated in the EcoRI and Xhol sites of the pcDNA3.1 mammalian expression vector. The sequence of this construct was verified by primers specific for aA-crystallin using $A B I$ 3700 automated DNA sequencer.

\subsection{Expression and purification of the recombinant wild type and R54C mutant protein}

For protein expression, plasmids containing the wild type and the mutant gene were transfected in Escherichia coli BL21 (DE3) cells. When the optical density of the culture reached 0.4 to $0.6 \mathrm{OD}$, protein expression was induced by the addition of IPTG $(1 \mathrm{mM})$. Cultures were incubated for $5 \mathrm{~h}$ at $37^{\circ} \mathrm{C}$ with stirring at $180 \mathrm{rpm}$. Cells were subsequently harvested by centrifugation at $3000 \times \mathrm{g}$. The cell pellet obtained was resuspended in $50 \mathrm{mM}$ Tris- $\mathrm{HCl}$ buffer ( $\mathrm{pH}$ 7.2) containing $100 \mathrm{mM} \mathrm{NaCl}$ and $1 \mathrm{mM}$ EDTA (TNE buffer), sonicated and centrifuged. The wild type as well as the mutant protein partitioned in the soluble fraction and were purified as described earlier [6]. Briefly, the soluble fraction was subjected to fractionation with ammonium sulphate (30$60 \%$ saturation) followed by gel filtration (Bio-Gel A-1.5m) and anion-exchange chromatography (Q-Sepharose). The concentrations of both the wild type and the mutant protein samples were estimated using its extinction coefficient $\left(14565 \mathrm{M}^{-1} \mathrm{~cm}^{-1}\right.$ for both proteins) at $280 \mathrm{~nm}$ as described by Pace et al. [66].

\subsection{Fluorescence studies}

The tryptophan fluorescence spectra of wild type and R54C aA-crystallin were monitored in TNE buffer with a protein concentration of $0.2 \mathrm{mg} \mathrm{ml}^{-1}$. Spectra were recorded using an excitation wavelength of $295 \mathrm{~nm}$ with excitation and emission band passes set at $2.5 \mathrm{~nm}$ each. Emission spectrum was recorded from $300 \mathrm{~nm}$ to $400 \mathrm{~nm}$. 
The surface hydrophobicity of the wild type and mutant proteins was probed by recording the fluorescence spectra of the hydrophobic probe, bis-ANS $(10 \mu \mathrm{M})$, as reported previously [67], upon incubation with $0.2 \mathrm{mg} \mathrm{ml}^{-1}$ of the respective protein samples at $25{ }^{\circ} \mathrm{C}$ for $10 \mathrm{~min}$. An excitation wavelength of $390 \mathrm{~nm}$ was used with excitation and emission band passes set at $2.5 \mathrm{~nm}$ each. Fluorescence spectra were recorded from 400 to $600 \mathrm{~nm}$. All spectra were recorded in the corrected spectrum mode using a Hitachi F-4500 fluorescence spectrophotometer.

\subsection{Local hydrophobicity prediction}

The hydrophobicity values around the wild type and mutated amino acid were predicted using the ProtScale online software at ExPASY server (http://web.expasy.org/protscale) with the Kyte-Doolittle hydrophobicity scale.

\subsection{Circular dichroism studies}

Circular dichroism spectra of the proteins were recorded as described previously [68]. Briefly, a concentration of $1.0 \mathrm{mg} \mathrm{ml}^{-1}$ of protein was used in TNE buffer in a $1 \mathrm{~cm}$ path length cell for near-UV region and a concentration of $0.2 \mathrm{mg} \mathrm{ml}^{-1}$ of protein in a 0.1 $\mathrm{cm}$ path length cell for the far-UV region. All spectra were recorded using a JASCO J715 spectropolarimeter at $25{ }^{\circ} \mathrm{C}$. The spectra reported are the average of 4 accumulations. Appropriate spectra of buffer blanks run under the same conditions were subtracted from the sample spectra and the observed ellipticity values were converted to mean residue ellipticity (MRE). CD data analysis was performed by using the CAPITO (CD Analysis and Plotting Tool) CD analysis online software, (Leibniz Institute on Aging - Fritz Lipmann Institute) [28].

\subsection{Size exclusion chromatography}

The oligomeric sizes of the wild type and mutant proteins were evaluated using a Superose-6 HR 10/30 pre-packed FPLC column (dimensions $1 \times 30 \mathrm{~cm}$ ). The proteins thyroglobulin $(669 \mathrm{kDa})$, ferritin $(440 \mathrm{kDa})$ and catalase $(232 \mathrm{kDa})$ were used as high molecular mass standards. 


\subsection{Dynamic light scattering studies}

For DLS studies, protein samples $\left(2 \mathrm{mg} \mathrm{ml}^{-1}\right)$ were centrifuged and filtered through a $0.22 \mu$ membrane filter. Measurements were carried out using a Photocor Dynamic Light Scattering Instrument (Photocor Instruments Inc., MD) equipped with a $633 \mathrm{~nm} 25 \mathrm{~mW}$ laser. All measurements were performed at $90^{\circ}$ angle with temperature set at $25^{\circ} \mathrm{C}$. Data was analysed using the Dynals (version 2.0) software provided with the instrument.

\subsection{Intracellular localization of wild type $\alpha$ A-crystallin and R54C mutant}

Human lens epithelial cells (SRA 01/04) were cultured in DMEM, supplemented with $10 \% \mathrm{FBS}$ and antibiotics $\left(5 \mathrm{\mu g} \mathrm{ml}^{-1}\right.$ penicillin \& $6 \mathrm{\mu g} \mathrm{ml}^{-1}$ streptomycin) at $37^{\circ} \mathrm{C}$ under $95 \%$ humidity and $5 \% \mathrm{CO}_{2}$. For transfection studies, SRA $01 / 04$ cells grown on cover-slips were transfected with $1 \mu \mathrm{g}$ of pcDNA3.1-N FLAG containing the wild type and mutant $\alpha \mathrm{A}$-crystallin using Lipofectamine 2000 reagent following the manufacturer's protocol.

Cells were fixed $48 \mathrm{~h}$ post transfection with $4 \%$ formaldehyde. The fixed cells were permeabilized with $0.05 \%$ Triton $X-100$ for 8 min. After blocking with $2 \%$ BSA, cells were incubated for $2 \mathrm{~h}$ with the desired primary antibodies against FLAG tag, $\mathrm{aB}$ crystallin, actin or Alexa Fluor ${ }^{\circledR} 488$ phalloidin (for staining actin filaments). Cells were then washed with PBS and further incubated with the corresponding secondary antibodies. Cells were counterstained with DAPI, and images were acquired using a $63 x$ objective lens on a Leica confocal microscope (TCS-SP8; Leica Microsystems, Wetzlar, Germany). Images were analysed by Leica Application Suite AF software provided by the company.

\subsection{Identification of interacting partners of wild type and mutant $\alpha A$-crystallin}

Cells were harvested $48 \mathrm{~h}$ post transfection by gentle scraping and whole cell protein was extracted by incubating cells in RIPA lysis buffer $(50 \mathrm{mM}$ Tris- $\mathrm{Cl}, \mathrm{pH}-7.4$, $150 \mathrm{mM} \mathrm{NaCl}, 1 \% \mathrm{NP}-40,0.5 \%$ sodium deoxycholate, $0.1 \%$ SDS) supplemented with 1 mM EDTA, $1 \mathrm{mM} \mathrm{PMSF}$ and $1 \mathrm{X}$ protease inhibitor cocktail for $30 \mathrm{~min}$ at $4{ }^{\circ} \mathrm{C}$. The lysate was centrifuged at $10,000 \times \mathrm{g}$ for $25 \mathrm{~min}$ at $4{ }^{\circ} \mathrm{C}$. The supernatant was pre-cleared by 
incubation with Protein $\mathrm{G}$ Sepharose beads for $1 \mathrm{~h}$ on a rotator at $4{ }^{\circ} \mathrm{C}$. After removing the Protein G Sepharose beads by centrifugation, the protein in the supernatant was estimated by Bradford's method according to the instructions of the manufacturer. Equal amounts of lysates for the two samples were further mixed with anti-FLAG antibody conjugated agarose beads and incubated overnight at $4^{\circ} \mathrm{C}$. Subsequently, the beads were washed thrice with Tris-buffered saline (TBS) and the proteins were eluted by adding Glycine-HCl (pH. 2.5). The eluted proteins were mixed with Laemmli buffer and loaded on a $4-12 \%$ precast Invitrogen Novex SDS gel followed by fixing and staining with Coomassie blue.

The preparation of gel slices followed by reduction, alkylation and in-gel protein digestion was done as described by Shevchenko et al.[69] The peptides were then desalted and enriched as described by Rappsilber et al.[70] Peptides eluted from desalting tips were dissolved in $2 \%(\mathrm{v} / \mathrm{v})$ formic acid and sonicated for $5 \mathrm{~min}$. Samples were analysed on a nanoflow LC system (Easy nLC II, Thermo Scientific) coupled to a Q-exactive mass spectrometer (Thermo Scientific). Peptides were separated on Bio Basic C18 pico-Frit nanocapillary column (75 $\mu \mathrm{m} \times 10 \mathrm{~cm}$; New objective, MA, USA) using a stepwise $60 \mathrm{~min}$ gradient between buffer A (5\% ACN containing $0.2 \%$ formic acid) and buffer B (95\% ACN containing $0.2 \%$ formic acid). The HPLC flow rate was set to $400 \mathrm{nl}$ per min during analysis. MS/MS analysis was performed with standard settings using cycles of 1 high resolution (70000 FWHM) MS scan (from $\mathrm{m} / \mathrm{z}$ 400-1600) followed by $10 \mathrm{MS} / \mathrm{MS}$ scans of the 10 most intense ions with charge states of 2 or higher. Protein identification and intensity based absolute quantification (iBAQ) [71] was performed using MaxQuant (version 1.3.0.5) [72] using default settings. The human sequences of UNIPROT (version 2016-03) were used as database for protein identification. MaxQuant used a decoy version of the specified UNIPROT database to adjust the false discovery rates for proteins and peptides below 1\%. Each experiment was repeated three times. Enrichment or depletion of an identified protein in at least two repeat experiments indicated alteration of abundance of the protein during the experiment. 


\subsection{Interaction of wild type and mutant $\alpha A$-crystallin with chromatin}

Cells were harvested $48 \mathrm{~h}$ post transfection as described by Kustatscher et al. [73], Briefly, cells were washed with PBS once $48 \mathrm{~h}$ post-transfection followed by treatment with pre-warmed $\left(37^{\circ} \mathrm{C}\right)$ formaldehyde $(1 \%)$ for $10 \mathrm{~min}$ at $37^{\circ} \mathrm{C}$. Glycine $(0.25 \mathrm{M})$ was used to quench the reaction followed by cell collection in PBS. The cells were lysed in lysis buffer (25 mM Tris ( $\mathrm{pH} 7.4), 0.1 \%$ Triton X-100 and $85 \mathrm{mM} \mathrm{KCl}$ supplemented with $1 \mathrm{X}$ protease inhibitor cocktail). The nuclei were separated by centrifugation at $2300 \times \mathrm{g}$ for $5 \mathrm{~min}$. The supernatant at this step was used to quantify the nuclei. The nuclei were then resuspended in lysis buffer and equal amounts of samples (based on the protein estimates in the supernatant) were treated with RNase $A$ followed by centrifugation at $2300 \times \mathrm{g}$ for $10 \mathrm{~min}$. The pellet was resuspended in SDS buffer (50 mM Tris (pH 7.4), 10 mM EDTA and 4\% SDS supplemented with 1X protease inhibitor cocktail) followed by the addition of urea buffer (10 mM Tris (pH 7.4), $1 \mathrm{mM}$ EDTA and $8 \mathrm{M}$ urea). The contents of the tubes were mixed thoroughly followed by centrifugation at $16,100 \times \mathrm{g}$ for $30 \mathrm{~min}$. The washing step (with SDS and urea buffer) was repeated once to wash contaminants followed by washing with just SDS buffer to remove urea. The final pellet was resuspended in storage buffer (10 mM Tris (pH 7.4), 1 mM EDTA, $25 \mathrm{mM} \mathrm{NaCl}$ and 10\% glycerol supplemented with 1X protease inhibitor cocktail). The samples were then sonicated for $15 \mathrm{~min}$ (30 sec on \& off pulse) followed by centrifugation at $16,100 \times \mathrm{g}$ for $30 \mathrm{~min}$. The supernatant was transferred to fresh tubes containing Laemmli buffer, boiled for $10 \mathrm{~min}$ and resolved on a $12 \%$ SDS PAGE for western blotting as described previously [74]. Briefly, the proteins, after resolving on $12 \%$ SDS PAGE were thereafter transferred to nitrocellulose membrane (Hybond Cextra) using a semi-dry transfer apparatus. The membrane was then placed in a blocking solution (5\% BSA in Tris Buffered Saline (TBS)) for $2 \mathrm{~h}$ followed by incubation with primary antibody (diluted in 1\% BSA in TBS) followed by washing (thrice) and incubation in Horseradish peroxidase (HRP) conjugated secondary antibody. The membrane was finally washed with TBS containing $0.1 \%$ Tween-20 (TBST) thrice and developed by Vilber-Lourmat Chemiluminescence Imaging System (MArne-la-Valée Cedex 3, France) using the Chemi-Capt software, after adding the HRP substrate. 
For immunofluorescence assay, transfected cells were fixed $48 \mathrm{~h}$ post transfection with $4 \%$ formaldehyde. The fixed cells were stained with the desired primary antibodies against FLAG tag and histone $\mathrm{H} 3$ followed by the corresponding secondary antibodies. Cells were counterstained with DAPI, and images were acquired using a $63 x$ objective lens on a Leica confocal microscope (TCS-SP8; Leica Microsystems, Wetzlar, Germany). Images were analyzed by Leica Application Suite AF software provided by the company.

\subsection{Cell death induced by R54C mutant of aA-crystallin}

Cells were harvested $48 \mathrm{~h}$ post transfection by gentle scraping and whole cell protein was extracted by incubating cells in lysis buffer $(50 \mathrm{mM}$ Tris $\mathrm{Cl}, \mathrm{pH} 8.0$, containing $1 \%$ Triton $\mathrm{X}-100,1 \%$ sodium deoxycholate, $0.1 \%$ sodium dodecyl sulphate, $150 \mathrm{mM}$ sodium chloride, $1 \mathrm{X}$ protease inhibitor, $1 \mathrm{X}$ phosphatase inhibitor and $1 \mathrm{mM}$ sodium orthovanadate) for 30 minutes on a rotator at $4{ }^{\circ} \mathrm{C}$. After a brief sonication, the lysate was centrifuged $\left(12,000 \times \mathrm{g}\right.$ for 20 minutes at $\left.4^{\circ} \mathrm{C}\right)$ to remove any aggregates. The protein in the supernatant was estimated by Bradford's method according to the instructions of the manufacturer. $25 \mu \mathrm{g}$ of the total cell protein was loaded on to a $12 \%$ SDS polyacrylamide electrophoresis gel. A similar protocol as mentioned in section 2.11 was used for western blotting using anti-caspase 3 antibody.

For MTT assay, cells were grown in 96 well plates and transfected accordingly. Cells were washed with PBS $48 \mathrm{~h}$ post transfection and incubated with MTT reagent dissolved in DMEM. The solution was removed after $4 \mathrm{~h}$ and the formazan crystals formed were dissolved in isopropanol. Absorbance at $570 \mathrm{~nm}$ was monitored using a 96 well plate reader.

\section{Acknowledgements}

SMA acknowledges Council for Scientific and Industrial Research (CSIR) for financial support. The authors thank Ms Shivali Rawat and Dr. Swasti Raychaudhuri for help and suggestions in proteomics data analysis. The authors also thank the proteomics facility of CCMB for the analysis. CMR acknowledges funding from the Sir J.C. Bose National Fellowship of the Dept. of Science and Technology, India. 


\section{Author contributions:}

Ch. Mohan Rao, Tangirala Ramakrishna, Bakthisaran Raman, and Saad M. Ahsan: Conceptualization, methodology and data analysis. Saad M. Ahsan: Experimentation and data acquisition. Ch. Mohan Rao, Tangirala Ramakrishna, Bakthisaran Raman, and Saad M. Ahsan: Writing, reviewing and editing. Ch. Mohan Rao: Supervision and funding acquisition.

\section{References}

[1] Quax-Jeuken Y., Quax W., Van Rens G., Khan P. M., Bloemendal H. (1985). Complete structure of the alpha B-crystallin gene: conservation of the exon-intron distribution in the two nonlinked alpha-crystallin genes. Proc. Natl. Acad. Sci. U. S. A. 82, 5819-23.

[2] Sax C. M. \& Piatigorsky J. (1994). Expression of the a-Crystallin/Small Heat-Shock Protein/Molecular Chaperone Genes in the Lens and other Tissues. Adv. Enzymol. Relat. Areas Mol. Biol. 69, 155-201.

[3] Ingolia T. D. \& Craig E. A. (1982). Four small Drosophila heat shock proteins are related to each other and to mammalian alpha-crystallin. Proc. Natl. Acad. Sci. U. S. A. $79,2360-4$.

[4] Horwitz J. (1992). Alpha-crystallin can function as a molecular chaperone. Proc. Natl. Acad. Sci. U. S. A. 89, 10449-53.

[5] Raman B. \& Rao C. M. (1994). Chaperone-like activity and quaternary structure of alpha-crystallin. J. Biol. Chem. 269, 27264-8.

[6] Sun T-X, Das B. K. \& Liang J. J-N. (1997). Conformational and functional differences between recombinant human lens $\alpha A$-and $\alpha B$-crystallin. J. Biol. Chem. 272, 6220-5.

[7] Kumar L. S., Ramakrishna T. \& Rao C. M. (1999). Structural and functional consequences of the mutation of a conserved arginine residue in $\mathrm{AA}$ and $\mathrm{aB}$ crystallins. J. Biol. Chem. 274, 24137-41.

[8] Datta S. A \& Rao C. M. (1999). Differential temperature-dependent chaperone-like activity of $\alpha A$-and $\alpha B$-crystallin homoaggregates. J. Biol. Chem. 274, 34773-8.

[9] Goenka S., Raman B., Ramakrishna T. \& Rao C. M. (2001). Unfolding and refolding of a quinone oxidoreductase: a-crystallin, a molecular chaperone, assists its reactivation. Biochem J. 359, 547-56.

[10] Rawat U. \& Rao M. (1998). Interactions of Chaperone a-Crystallin with the Molten Globule State of Xylose Reductase IMPLICATIONS FOR RECONSTITUTION OF THE ACTIVE ENZYME. J. Biol. Chem. 273, 9415-23. 
[11] Nath D., Rawat U., Anish R. \& Rao M. (2002). a-Crystallin and ATP facilitate the in vitro renaturation of xylanase: enhancement of refolding by metal ions. Protein Sci. 11, 2727-34.

[12] Rajaraman K., Raman B., Ramakrishna T. \& Rao C. (2001). Interaction of human recombinant $\alpha \mathrm{A}$-and $\mathrm{aB}$-crystallins with early and late unfolding intermediates of citrate synthase on its thermal denaturation. FEBS letters. 497, 118-23.

[13] Hook D. W. \& Harding J. J. (1997). Molecular chaperones protect catalase against thermal stress. Eur J Biochem. 247, 380-5.

[14] Marini I., Moschini R., Del Corso A. \& Mura U. (2000). Complete protection by acrystallin of lens sorbitol dehydrogenase undergoing thermal stress. J. Biol. Chem. 275, 32559-65.

[15] Hess J. F. \& FitzGerald P. G. (1998). Protection of a restriction enzyme from heat inactivation by [alpha]-crystallin. Mol Vis. 4, 29-32.

[16] Kumar L. S. \& Rao C. M. (2000). Domain swapping in human aA and aB crystallins affects oligomerization and enhances chaperone-like activity. J. Biol. Chem. 275, 22009-13.

[17] Ghosh J. G., Estrada M. R. \& Clark J. I. (2005). Interactive domains for chaperone activity in the small heat shock protein, human aB crystallin. Biochemistry. 44,14854-69.

[18] Pasta S. Y., Raman B., Ramakrishna T. \& Rao C. M. (2003). Role of the Conserved SRLFDQFFG Region of a-Crystallin, a Small Heat Shock Protein EFFECT ON OLIGOMERIC SIZE, SUBUNIT EXCHANGE, AND CHAPERONE-LIKE ACTIVITY. J. Biol. Chem. 278, 51159-66.

[19] Kundu M., Sen P. C. \& Das K. P. (2007). Structure, stability, and chaperone function of aA-crystallin: Role of N-terminal region. Biopolymers. 86, 177-92.

[20] Graw J., Klopp N., Illig T., Preising M. N. \& Lorenz B. (2006). Congenital cataract and macular hypoplasia in humans associated with a de novo mutation in CRYAA and compound heterozygous mutations in P. Graefes Arch. Clin. Exp. Ophthalmol. 244, 912-9.

[21] Javadiyan S., Craig J. E., Souzeau E., Sharma S., Lower K. M., Pater J., Casey T., Hodson T., Burdon K. P. (2016). Recurrent mutation in the crystallin alpha A gene associated with inherited paediatric cataract. BMC Res. Notes. 9, 83.

[22] Devi R. R., Yao W., Vijayalakshmi P., Sergeev Y. V., Sundaresan P. \& Hejtmancik J. F. (2008). Crystallin gene mutations in Indian families with inherited pediatric cataract. Mol Vis. 14, 1157-70.

[23] Khan A. O., Aldahmesh M. A. \& Meyer B. (2007). Recessive congenital total cataract with microcornea and heterozygote carrier signs caused by a novel missense CRYAA mutation (R54C). Am J Ophthalmol. 144, 949-52. 
[24] Mackay D. S., Andley U. P. \& Shiels A. (2003). Cell death triggered by a novel mutation in the alphaA-crystallin gene underlies autosomal dominant cataract linked to chromosome 21q. Eur J Hum Genet. 11, 784-93.

[25] Kore R., Hedges R. A., Oonthonpan L., Santhoshkumar P., Sharma K. K., Abraham E. C. (2012). Quaternary structural parameters of the congenital cataract causing mutants of aA-crystallin. Mol Cell Biochem. 362, 93-102.

[26] Khoshaman K., Yousefi R., Tamaddon A. M., Abolmaali S. S., Oryan A., MoosaviMovahedi A. A. \& Kurganov B. I. (2017). The impact of different mutations at Arg54 on structure, chaperone-like activity and oligomerization state of human aA-crystallin: The pathomechanism underlying congenital cataract-causing mutations R54L, R54P and R54C. Biochim Biophys Acta Proteins Proteom. 1865(5), 604-618.

[27] Huang Q., Ding L., Phan K. B., Cheng C., Xia C-h, Gong X. \& Horwitz J. (2009). Mechanism of cataract formation in aA-crystallin Y118D mutation. Invest Ophthalmol Vis Sci. 50, 2919-26.

[28] Wiedemann C., Bellstedt P. \& Gorlach M. (2013). CAPITO--a web server-based analysis and plotting tool for circular dichroism data. Bioinformatics. 29, 1750-7.

[29] Hirst J. D., Bhattacharjee S. \& Onufriev A. V. (2003). Theoretical studies of timeresolved spectroscopy of protein folding. Faraday discussions. 122, 253-67.

[30] Musci G., Metz G. D., Tsunematsu H. \& Berliner L. J. J. B. (1985). 4, 4'-Bis [8(phenylamino) naphthalene-1-sulfonate] binding to human thrombins: a sensitive exo site fluorescent affinity probe. Biochemistry. 24, 2034-9.

[31] Wang X., Garcia C. M., Shui Y-B \& Beebe D. C. (2004). Expression and regulation of $\alpha-, \beta-$, and $y$-crystallins in mammalian lens epithelial cells. Invest Ophthalmol Vis Sci. 45, 3608-19.

[32] Andley U. P., Malone J. P. \& Townsend R. R. (2014). In vivo substrates of the lens molecular chaperones alphaA-crystallin and alphaB-crystallin. PLoS One. 9, e95507.

[33] Bakthisaran R., Tangirala R. \& Rao C. M. (2015). Small heat shock proteins: role in cellular functions and pathology. Biochim Biophys Acta. 1854 (4), 291-319.

[34] Andley U. P. (2007). Crystallins in the eye: Function and pathology. Prog Retin Eye Res. 26, 78-98.

[35] Bhagyalaxmi S., Srinivas P., Barton K. A., Kumar K. R., Vidyavathi M., Petrash J. M., Bhanuprakash Reddy G., Padma T. (2009). A novel mutation (F71L) in aA-crystallin with defective chaperone-like function associated with age-related cataract. Biochim Biophys Acta.1792, 974-81.

[36] Singh D., Raman B., Ramakrishna T. \& Rao Ch. M. (2006). The cataract-causing mutation G98R in human alphaA-crystallin leads to folding defects and loss of chaperone activity. Mol Vis. 12, 1372-9. 
[37] Bova M. P., Yaron O., Huang Q., Ding L., Haley D. A., Stewart P. L. \& Horwitz J. (1999). Mutation R120G in aB-crystallin, which is linked to a desmin-related myopathy, results in an irregular structure and defective chaperone-like function. Proc Natl Acad Sci U S A. 96, 6137-42.

[38] Raju M., Santhoshkumar P. \& Sharma K. K. (2011). Cataract-causing aAG98Rcrystallin mutant dissociates into monomers having chaperone activity. Mol Vis. 17, 715.

[39] Singh D., Tangirala R., Bakthisaran R. \& Chintalagiri M. R. (2009). Synergistic effects of metal ion and the pre-senile cataract-causing G98R aA-crystallin: selfaggregation propensities and chaperone activity. Mol Vis. 15, 2050-60.

[40] Chen Q., Yan M., Xiang F., Zhou X., Liu Y. \& Zheng F. (2010). Characterization of a mutant $\mathrm{R} 11 \mathrm{H}$ aB-crystallin associated with human inherited cataract. Biol Chem. 391, 1391-400.

[41] Hayes V. H., Devlin G. \& Quinlan R. A. (2008). Truncation of aB-crystallin by the myopathy-causing Q151X mutation significantly destabilizes the protein leading to aggregate formation in transfected cells. J. Biol. Chem. 283, 10500-12.

[42] Adhikari A. S., Singh B. N., Rao K. S. \& Rao C. M. (2011). aB-crystallin, a small heat shock protein, modulates NF-kB activity in a phosphorylation-dependent manner and protects muscle myoblasts from TNF-a induced cytotoxicity. Biochim Biophys Acta. 1813, 1532-42.

[43] Raju I. \& Abraham E. C. (2011). Congenital cataract causing mutants of aAcrystallin/sHSP form aggregates and aggresomes degraded through ubiquitinproteasome pathway. PLoS One. 6, e28085.

[44] Thomas J. O., Kornberg R. D. (1975). An octamer of histones in chromatin and free in solution. Proc. Natl. Acad. Sci. U. S. A. 72, 2626-30.

[45] Andley U. P., Patel H. C. \& Xi J. H. (2002). The R116C mutation in alpha Acrystallin diminishes its protective ability against stress-induced lens epithelial cell apoptosis. J. Biol. Chem. 277, 10178-86.

[46] Hamilton P. D. \& Andley U. P. (2018). In vitro interactions of histones and acrystallin . Biochem Biophys Rep. 15, 7-12.

[47] Sidjanin D., Grdina D. \& Woloschak G. E. (1996). UV-induced changes in cell cycle and gene expression within rabbit lens epithelial cells. Photochem Photobiol. 63, 79-85.

[48] Andley U. P., Tycksen E., McGlasson-Naumann B. N., Hamilton P. D. (2018). Probing the changes in gene expression due to a-crystallin mutations in mouse models of hereditary human cataract. PLoS One 13(1), e0190817. 
[49] Chen Y., Stump R. J., Lovicu F. J., Shimono A., McAvoy J. W. (2008). Wnt signaling is required for organization of the lens fiber cell cytoskeleton and development of lens three-dimensional architecture. Dev Biol. 324, 161-76.

[50] Antosova B., Smolikova J., Borkovcova R., Strnad H., Lachova J., Machon O., Kozmik Z. (2013). Ectopic activation of Wnt/ $\beta$-catenin signaling in lens fiber cells results in cataract formation and aberrant fiber cell differentiation. PLoS One. 8, e78279.

[51] Nishiyama M., Skoultchi A. I. \& Nakayama K.I. (2012). Histone H1 recruitment by CHD8 is essential for suppression of the Wnt-beta-catenin signaling pathway. Mol Cell Biol. 32, 501-12.

[52] Bassnett S., Shi Y. \& Vrensen G. F. J. M. (2011). Biological glass: structural determinants of eye lens transparency. Philos Trans R Soc Lond B Biol Sci. 366, 125064.

[53] Muchowski P. J., Valdez M. M. \& Clark J. I. (1999). AlphaB-crystallin selectively targets intermediate filament proteins during thermal stress. Invest Ophthalmol Vis Sci. 40, 951-8.

[54] Singh B. N., Rao K. S., Ramakrishna T., Rangaraj N. \& Rao C. M. (2007). Association of aB-crystallin, a small heat shock protein, with actin: role in modulating actin filament dynamics in vivo. J Mol Biol. 366, 756-67.

[55] Fujita Y., Ohto E., Katayama E. \& Atomi Y. alphaB-Crystallin-coated MAP microtubule resists nocodazole and calcium-induced disassembly. J Cell Sci. 117, 1719-26.

[56] Brown Z., Ponce A., Lampi K., Hancock L. \& Takemoto L. (2007). Differential binding of mutant (R116C) and wildtype alphaA crystallin to actin. Curr Eye Res. 32, 1051-4.

[57] Mehlen P., Kretz-Remy C., Preville X. \& Arrigo A-P. (1996). Human hsp27, Drosophila hsp27 and human alphaB-crystallin expression-mediated increase in glutathione is essential for the protective activity of these proteins against TNFalphainduced cell death. EMBO J. 15, 2695.

[58] Mehlen P., Schulze-Osthoff K. \& Arrigo A-P. (1996). Small stress proteins as novel regulators of apoptosis heat shock protein 27 blocks Fas/APO-1-and staurosporineinduced cell death. J Biol Chem. 271, 16510-4.

[59] Kamradt M. C., Chen F. \& Cryns V. L. (2001). The small heat shock protein aBcrystallin negatively regulates cytochrome c-and caspase-8-dependent activation of caspase-3 by inhibiting its autoproteolytic maturation. J Biol Chem. 276, 16059-63. 
[60] McGreal R. S., Kantorow W. L., Chauss D. C., Wei J., Brennan L. A. \& Kantorow M. (2012). aB-crystallin/sHSP protects cytochrome $c$ and mitochondrial function against oxidative stress in lens and retinal cells. Biochim Biophys Acta. 1820, 921-30.

[61] Mao Y., Liu J., Xiang H. \& Li D. W. (2004). Human aA-and aB-crystallins bind to $\mathrm{Bax}$ and $\mathrm{Bcl}-\mathrm{Xs}$ to sequester their translocation during staurosporine-induced apoptosis. Cell Death Differ. 11, 512-26.

[62] Morozov V. \& Wawrousek E. F. (2006). Caspase-dependent secondary lens fiber cell disintegration ina A-/aB-crystallin double-knockout mice. Development. 133, 81321.

[63] Raju I. \& Abraham E. C. (2013). Mutants of human aB-crystallin cause enhanced protein aggregation and apoptosis in mammalian cells: influence of co-expression of HspB1. Biochem Biophys Res Commun. 430, 107-12.

[64] Ross C. A. (2002). Polyglutamine pathogenesis: emergence of unifying mechanisms for Huntington's disease and related disorders. Neuron. 35, 819-22.

[65] Sandilands A., Hutcheson A. M, Long H. A., Prescott A. R., Vrensen G., Löster J., Klopp N., Lutz R. B., Graw J., Masaki S., Dobson C. M., MacPhee C. E., Quinlan R. A. (2002). Altered aggregation properties of mutant y-crystallins cause inherited cataract. EMBO J. 21, 6005-14.

[66] Pace C. N, Vajdos F., Fee L., Grimsley G. \& Gray T. (1995). How to measure and predict the molar absorption coefficient of a protein. Protein Sci. 4, 2411-23.

[67] Ahsan S. M, Rao C. M. (2017). The role of surface charge in the desolvation process of gelatin: implications in nanoparticle synthesis and modulation of drug release. Int J Nanomedicine12, 795-808.

[68] Ahsan S. M., Rao C. M. (2017). Structural studies on aqueous gelatin solutions: Implications in designing a thermo-responsive nanoparticulate formulation. Int. J. Biol. Macromol 95, 1126-34.

[69] Shevchenko A., Wilm M., Vorm O. \& Mann M. (1996). Mass spectrometric sequencing of proteins silver-stained polyacrylamide gels. Anal Chem. 68, 850-8.

[70] Rappsilber J., Ishihama Y. \& Mann M. (2003) Stop and go extraction tips for matrixassisted laser desorption/ionization, nanoelectrospray, and LC/MS sample pretreatment in proteomics. Anal Chem. 75, 663-70.

[71] Schwanhäusser B., Busse D., Li N., Dittmar G., Schuchhardt J., Wolf J., Chen W. \& Selbach M. (2011). Global quantification of mammalian gene expression control. Nature. 473, 337-342. 
[72] Cox J. \& Mann M. (2008). MaxQuant enables high peptide identification rates, individualized ppb-range mass accuracies and proteome-wide protein quantification. Nat Biotechnol. 26(12), 1367-72.

[73] Kustatscher G., Wills K. L., Furlan C. \& Rappsilber J. (2014). Chromatin enrichment for proteomics. Nat Protoc. 9, 2090-9.

[74] Ahsan S. M., Rao C. M. (2017). Condition responsive nanoparticles for managing infection and inflammation in keratitis. Nanoscale 9, 9946-59. 